\title{
The interaction of organic and geogenic nutrient cycles
}

\author{
DAVID UHLIG ${ }^{1,2}$ AND FRIEDHELM VON \\ BLANCKENBURG $^{3}$
}

${ }^{1}$ Forschungszentrum Jülich GmbH

${ }^{2}$ German Research Centre for Geosciences

${ }^{3}$ GFZ German Research Centre for Geosciences

Presenting Author: d.uhlig@fz-juelich.de

Primary productivity depends on nutrient availability. As trees thrive on soils regardless of its nutrient status, trees can be considered as real masters in adapting to the nutrient status of the soil that hosts them. To gain insights into forest ecosystem nutrition at contrasting nutrient availability we i) geochemically conceptualised a forest ecosystem by partitioning into the socalled "organic nutrient cycle" and the "geogenic nutrient pathway", and ii) quantified deep (up to $30 \mathrm{~m}$ depth) weathering and mineral nutrient cycling in two montane, temperate forest ecosystems in Southern Germany.

The organic nutrient cycle comprises trees and the forest floor, and is characterized by nutrient uptake from and return to the forest floor from which organic-bound nutrients are re-utilized. The geogenic nutrient pathway comprises the mineral soil and the weathering zone beneath it, and is characterized through regolith production (conversion of rock into regolith) at depth, driven by erosion at the surface, and chemical weathering, which liberates mineral nutrients across the weathering zone. Both cycles are coupled to compensate for the permanent loss of organic-bound nutrients in particulate (e.g., plant litter) and solute form. This loss occurs slowly but steadily in sloping, welldrained landscapes.

From measurements of the inventories and fluxes of macronutrients $(\mathrm{K}, \mathrm{Ca}, \mathrm{Mg}, \mathrm{P})$ we found vast differences in turnover times between the two cycles. For example, about 960 $\mathrm{mg} \mathrm{P} \mathrm{m}{ }^{-2}$ and $6400 \mathrm{mg} \mathrm{K} \mathrm{m}^{-2}$ were annually utilized by trees but only about $84 \mathrm{mg} \mathrm{P} \mathrm{m}^{-2}$ and $1000 \mathrm{mg} \mathrm{K} \mathrm{m}^{-2}$ were annually supplied by rock weathering. Hence, the organic nutrient cycle apparently regulates the efficiency of nutrient re-utilization from organic matter to cater for differences in geogenic-derived nutrient supply fluxes from rock weathering. 